\title{
Sentimentos e atitudes de crianças em relação aos maus tratos a pessoas idosas
}

\author{
Children's feelings and attitudes regarding elder abuse
}

Sentimientos y actitudes de niños en relación a malos tratos a personas ancianas

Bruna Moretti Luchesi ${ }^{1}$, Giselle Dupas ${ }^{2}$, Luzia Cristina Antoniossi Monteiro ${ }^{3}$, Sueli Marques ${ }^{4}$, Sofia Cristina lost Pavarini ${ }^{5}$

${ }^{1}$ Enfermeira, Mestre em Enfermagem. Discente do Programa de Pós-Graduação em Enfermagem Fundamental da Escola de Enfermagem de Ribeirão Preto da Universidade de São Paulo (PPGEF/EERP/USP). Ribeirão Preto, SP, Brasil. E-mail: brunaluchesi@usp.br.

${ }^{2}$ Enfermeira, Doutora em Enfermagem. Professora Associada do Departamento de Enfermagem da Universidade Federal de São Carlos (UFSCar). São

Carlos, SP, Brasil. E-mail: gdupas@ufscar.br.

${ }_{3}^{3}$ Advogada, Doutorado em Engenharia Urbana. Professor Adjunto Departamento de Gerontologia da UFSCar. São Carlos, SP, Brasil. E-mail: cristinaantoniossi4@gmail.com.

${ }^{4}$ Enfermeira, Doutora em Enfermagem Fundamental. Professora Doutora da EERP/USP. Ribeirão Preto, SP, Brasil. E-mail: smarques@eerp.usp.br.

${ }^{5}$ Enfermeira, Doutora em Educação. Professora Associada do Departamento de Gerontologia da UFSCar. E-mail: sofia@ufscar.br.

\section{RESUMO}

O estudo objetivou conhecer sentimentos e atitudes de crianças em relação aos maus tratos contra idosos. Estudo de abordagem qualitativa para o qual foram entrevistadas 52 crianças de sete a dez anos de idade utilizando-se de questões abertas. As respostas foram gravadas, transcritas e realizou-se análise de conteúdo, modalidade temática. Foram identificados dois grandes temas: Reação das crianças diante dos maus tratos aos idosos, tema no qual a categoria mais citada foi "ajudando de alguma forma", seguida de "não sabendo o que fazer temendo represálias" e "reagindo da mesma maneira com o agressor"; Sentimento das crianças diante dos maus tratos aos idosos, no qual as categorias foram "ficando triste/chateado", "reconhecendo o idoso como frágil" e "não identificando o sentimento". Explorar percepções das crianças sobre tema de relevância social como os maus tratos aos idosos torna possível que profissionais de saúde desenvolvam estratégias para informá-las e instrumentalizá-las sobre o assunto.

Descritores: Maus-Tratos ao Idoso; Criança; Enfermagem.

\section{ABSTRACT}

The objective of this study was to understand children's feelings and attitudes regarding elder abuse. This qualitative study was performed with 52 children of ages between seven and ten years, who were interviewed using open questions. The answers were recorded, transcribed and submitted to thematic content analysis. Two large themes were identified: The children's reaction in face of elder abuse, a theme in which the most stated category was "doing something to help", followed by "not knowing what to do due to the fear of punishment" and "reacting the same way against the assailant"; The children's feelings in face of elder abuse, which comprised the categories "becoming sad/upset", "recognizing the elder as frail" and "not being able to identify the feeling". By exploring children's perceptions regarding themes with social relevance, such as elder abuse, permits healthcare professionals to develop strategies to inform and support them regarding the issue.

Descriptors: Elder Abuse; Child; Nursing.

\section{RESUMEN}

Se objetivó conocer sentimientos y actitudes de niños en relación a malos tratos contra ancianos. Estudio cualitativo, para el que fueron entrevistados 52 niños de siete a diez años, utilizándose preguntas abiertas. Las respuestas fueron grabadas, transcriptas, y se realizó análisis de contenido, modalidad temática. Se identificaron dos grandes temas: Reacción de los niños ante los malos tratos a ancianos, tema en el cual la categoría más citada fue "ayudando de alguna forma", seguida de "no sabiendo qué hacer, temiendo represalias" y "reaccionando de la misma manera con el agresor"; y Sentimiento de los niños ante los malos tratos a ancianos, en el cual las categorías fueron "entristecido/enojado", "reconociendo al anciano como frágil" y “no identificando el sentimiento". Explorar percepciones de los niños sobre tema de relevancia social como malos tratos a ancianos hace posible que los profesionales de salud desarrollen estrategias para informarlos e instrumentalizarlos sobre el asunto.

Descriptores: Maltrato al Anciano; Niño; Enfermería. 


\section{INTRODUÇÃO}

A violência é uma manifestação crescente na sociedade moderna, sendo dirigida prioritariamente às pessoas mais vulneráveis, como crianças, mulheres, idosos e portadores de deficiência ${ }^{(1)}$. Sua prevalência é de difícil constatação, já que as informações disponíveis em delegacias e locais especializados no atendimento a esta população só contam com dados de casos denunciados e atendidos, deixando de fora muitos casos que permanecem ocultos e sem atendimento.

De acordo com a Rede Internacional para a Prevenção do Abuso ao Idoso, o abuso pode ser definido como ato único ou repetido, ou ainda ausência de ação apropriada, que cause dano ou angústia e ocorra em um relacionamento onde haja confiança(2).

No Brasil, esta definição foi adotada pelo Ministério da Saúde em 2001, o qual sugeriu o uso do termo maus tratos, por representar uma ação e possuir diferentes tipos e categorias ${ }^{(3)}$. Os maus tratos contra idosos incluem abuso físico, sexual, psicológico, financeiro e a negligência. É uma violação dos direitos humanos, geralmente pouco denunciada(4).

Em relação aos maus tratos aos idosos, em 1975 surgiram os primeiros relatos britânicos de violência contra os avós, porém o tema levou cerca de 10 anos para se tornar alvo de pesquisas mais sistematizadas ${ }^{(5)}$.

A primeira pesquisa de prevalência de maus tratos em idosos foi realizada nos Estados Unidos, em 1981, e constatou-se que menos de $4 \%$ dos idosos já haviam sofrido algum tipo de abuso e somente um em cada seis casos era denunciado. O primeiro relatório sobre violência contra idosos da Organização Mundial da Saúde (OMS) dizia que a taxa de incidência variava de $4 \%$ a $6 \%$ nos estudos já realizados. Na América Latina, a primeira publicação sobre o tema foi conduzida na Argentina, em 1989(5-6).

A atenção especial a este assunto deve crescer devido ao aumento do número de pessoas com 60 anos ou mais de idade na população, o que pode levar ao aumento do surgimento de doenças crônicas não transmissíveis, gerando incapacidade funcional e, consequentemente, maior dependência do idoso para desenvolver suas atividades. A dependência é um fator de risco para tornar o idoso vulnerável a alguma das formas de maus tratos ${ }^{(5,7)}$.

A conscientização da população de maneira geral, em especial dos mais jovens, pode modificar uma estrutura que está se formando de maneira frágil. Hoje a violência já pode ser considerada um problema de saúde pública e há a necessidade de desenvolver estudos que abordem maus tratos contra idosos em diferentes comunidades, utilizando diversas metodologias e instrumentos ${ }^{(3,8)}$.

Um estudo conduzido com 2.077 crianças da Nova Zelândia para verificar a percepção das mesmas sobre a violência concluiu que presenciar a violência contra outras pessoas, principalmente as mais velhas, causa mais impacto nas crianças do que a violência sofrida contra elas próprias $^{(9)}$. Além disso, as consequências emocionais e afetivas para as crianças que vivenciam situações de violência são relevantes, pois podem interferir no comportamento e desenvolvimento das mesmas ${ }^{(10)}$.

Em entrevistas com oito crianças de nove a onze anos, de Niterói-RJ, identificou-se que a violência na comunidade é relatada como próxima pelas crianças, já que elas percebem os episódios e acontecimentos relacionados aos maus tratos na sociedade em que estão inseridas e são capazes de expor seus sentimentos e opiniões de modo crítico(11).

Desde o nascimento, a criança interage com o mundo e vai recebendo informações que seleciona de acordo com seu nível cognitivo, criando suas próprias representações do mundo, como faz com a temática dos maus tratos. Porém, há pouca discussão do assunto nos locais em que as crianças frequentam, e para que uma educação de conscientização se concretize, é preciso saber o que as crianças pensam, como pensam e como interpretam a violência(12).

Apesar do interesse na temática da violência ter crescido bastante nos últimos tempos, o conhecimento produzido sobre a visão das crianças em relação a ela ainda é escasso(9). Conhecer a percepção de crianças sobre o assunto é um passo importante para subsidiar a implementação de políticas contra a violência e focar na conscientização, já que muitos comportamentos e atitudes apreendidos precocemente na vida podem persistir ${ }^{(13)}$.

Diante do aumento do número de idosos na população e consequente aumento das relações intergeracionais ${ }^{(7-8)}$; das crescentes manifestações dos maus tratos contra idosos $(1,3,7,8)$; do fato de que as crianças são capazes de perceber esses episódios e expor o que sentem ${ }^{(11-12)}$; e da importância de se conhecer a percepção de crianças em relação ao tema, para que seja possível planejar intervenções ${ }^{(11-13)}$, foi proposto o objetivo de 
conhecer os sentimentos e atitudes de crianças sobre maus tratos aos idosos.

\section{MÉTODOS}

Trata-se de estudo descritivo, transversal e qualitativo, realizado em um município do interior paulista.

Foram sujeitos desta pesquisa crianças de sete a dez anos de idade $(n=52)$, cadastradas em cinco diferentes Unidades de Saúde da Família (USF). A seleção foi realizada por meio da ficha de cadastramento das famílias nas USF, na qual consta o nome e idade de todas as pessoas que moram na casa.

Os critérios de inclusão foram: ter entre sete e dez anos, ser cadastrado em uma das USF selecionadas, morar com pelo menos um idoso ( $\geq 60$ anos), ser encontrado na residência (máximo duas tentativas) e não ter se mudado do endereço que constava no cadastro. Optou-se por selecionar crianças que moravam com idosos devido ao fato de que os maus tratos contra idosos, normalmente, ocorrem no ambiente domiciliar e dentro da família ${ }^{5,7,14-}$ 15), assim as crianças poderiam ter tido mais contato com o tema em questão.

Após busca nos cadastros das USF, 103 crianças foram identificadas, sendo excluídas 21 que não se encontravam em suas residências, 27 que haviam mudado de endereço, um caso de falecimento do idoso e duas recusas na participação, totalizando 52 sujeitos pesquisados. Apesar de nas pesquisas qualitativas o número de sujeitos não ser definido a priori, optou-se por entrevistar a totalidade das crianças encontradas de acordo com os critérios de inclusão, para se obter uma visão ampliada sobre a temática.

Para a coleta de dados, foram realizadas entrevistas pela pesquisadora principal no domicílio da criança, agendadas de acordo com a disponibilidade dessa e de seus pais ou responsáveis, no período de junho a agosto de 2009. A coleta de dados teve início após a leitura e assinatura do Termo de Consentimento Livre e Esclarecido pelos responsáveis das crianças.

As crianças foram entrevistadas por meio de duas questões disparadoras, sendo elas: "Você já viu alguém maltratando um idoso? Se sim, como você se sentiu, e você fez alguma coisa? Se não, como se sentiria se visse, e faria alguma coisa?". As entrevistas foram gravadas com auxílio de um gravador, com duração média de oito minutos, e transcritas posteriormente.

Os dados foram analisados de acordo com a análise de conteúdo temático, proposta por Bardin, procurando as regularidades nos discursos, identificando os núcleos do sentido, categorizando e avaliando os mesmos, e seguindo três etapas: pré-análise (leitura flutuante e escolha dos documentos), exploração do material (decomposição do texto em categorias) e tratamento, inferência e interpretação dos resultados obtidos, sendo que foi utilizado o sistema de análise por milhas ${ }^{(16)}$. Foi identificada a frequência de citação das categorias encontradas, as quais serão apresentadas em forma de porcentagem.

Os dados de caracterização sociodemográfica das crianças abarcaram nome, endereço, USF de referência, sexo, idade, escolaridade, número de pessoas na casa, grau de parentesco dela em relação ao idoso com quem mora e há quanto tempo mora com o idoso.

O projeto foi aprovado pelo Comitê de Ética em Pesquisa da Universidade Federal de São Carlos (Parecer $n^{\circ}$ 486/2008). Рara garantir o anonimato dos sujeitos, quando foram relatadas as entrevistas foram citados: o número da entrevista, as iniciais e idade da criança, entre parênteses, e após a transcrição da fala da mesma, seguindo o exemplo: (21-BML-10anos). Salienta-se que as entrevistas estão numeradas do número um ao 52, ordem em que as mesmas foram realizadas.

\section{RESULTADOS E DISCUSSÃO}

As crianças entrevistadas eram, em sua maioria, do sexo masculino (57,7\%), com média de 8,6 anos, e frequentavam a $4^{\mathrm{a}}$ série do Ensino Fundamental (44,2\%). A maioria era neta do idoso (86,6\%) e morava com ele há mais de cinco anos (75\%). O número de pessoas que morava na casa variou entre duas (a criança e o idoso) e 12 , com média de 5,96 pessoas.

O conhecimento dos sentimentos e atitudes apresentados nas falas das crianças em relação aos maus tratos contra idosos serão descritos a partir de dois grandes temas e suas respectivas categorias temáticas, apresentadas na Figura 1. 
Figura 1. Temas e categorias relacionados aos sentimentos e atitudes das crianças diante dos maus tratos contra idosos. São Carlos-SP, 2009

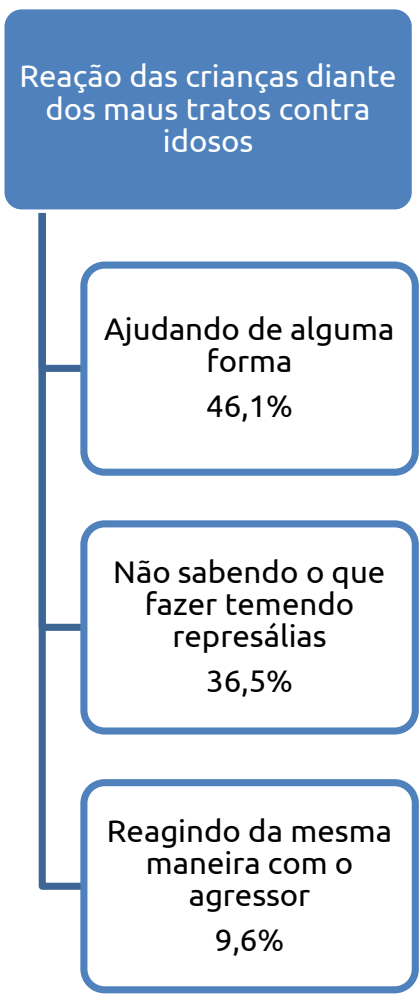

A seguir será detalhado o conteúdo dos temas e categorias identificados.

\section{Reação das crianças diante dos maus tratos com idosos}

Este tema foi dividido em três categorias, de acordo com as respostas das crianças: Ajudando de alguma forma, Não sabendo o que fazer e Reagindo da mesma maneira com o agressor. As três categorias serão apresentadas a seguir.

\section{Ajudando de alguma forma}

Foram agrupados, neste tema, os depoimentos das crianças que citaram que ajudariam de alguma maneira o idoso que está sendo agredido. As formas de ajuda citadas foram: pedir auxílio de um adulto, denunciar o agressor, separar a briga, pedir para o agressor parar, ajudar o idoso e aconselhar o idoso. Solicitar auxílio de um adulto foi lembrado por algumas crianças como forma de ajudar o idoso, como se vê nas falas abaixo:

Se eu visse? Se eu tivesse do lado da minha mãe eu falava pra minha mãe, oh mãe, aquela pessoa idosa tá apanhando. Aí eu ia pedir pra ela fazer alguma coisa (6-VB-9anos).

Eu contei pra Camila, e ela deu um xingo neles (18-VGGCS8anos).

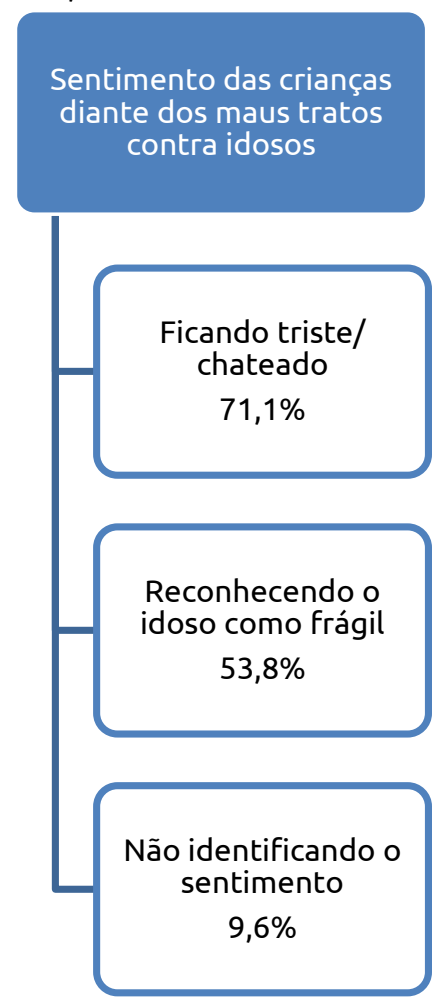

Assim, eu falo pra minha avó que eu fico preocupada (52TCVC-9anos).

Também foi destacada outra forma de pedir auxílio a um adulto, mas de forma profissional, para que o agressor fosse punido pelo que estava fazendo.

Eu ia ligar pra polícia, ué! (15-AJNJ-9anos).

Ah, quem maltrata deve ser preso, pagar uns dinheirinho (21-GBP-9anos).

Podia ter processado a pessoa (23-JHSC-10anos).

Ou ainda solicitando auxílio médico para cuidar do idoso.

Eu ia, ia levar pra um médico (38-MMC-8anos).

Ajudar o idoso sem auxílio de adultos foi destacado por algumas crianças, sendo que as próprias tomariam alguma atitude na presença de um ato de mau trato. Algumas disseram apenas que ajudariam, mas não citaram como.

Aham, eu ia ajudar né (42-MVGB-10anos). 
Outros sujeitos disseram que ajudariam de diversas formas como, por exemplo, separando a briga ou pedindo para o agressor parar.

Hum, ia separar a briga (11-FAM-8anos).

Eu ia falar para eles parar (12-KHM-8anos).

la chamar atenção (26-ACVV-9anos).

Eu ia falar para ele num bater e não xingar (28-VT-8anos).

Algumas crianças aconselhariam o agressor, fazendoo pensar sobre o seu futuro como uma pessoa idosa e sobre aquele ato que praticou como um pecado, voltando para a questão da religiosidade.

Ah, eu ia falar pra ele pensar bem porque um dia ele pode ficar pior que aquela pessoa (16-KLS-9anos).

É pecado (49-BGSF-9anos).

[...] e é pecado fazer isso (50-LJSV-7anos).

\section{Não sabendo o que fazer temendo represálias}

Nesta categoria foram incluídos os relatos de crianças que não sabem o que fariam ou não fariam nada, caso presenciassem uma cena de maus tratos aos idosos. Puderam ser observadas algumas falas em que as crianças disseram que não fariam nada, com medo das consequências, caso tomassem alguma atitude.

Senão eu ia pra cadeia (13-TSC-7anos).

Minha irmã, ela trata mal, fica xingando. Não faço nada, senão ela fica brava comigo também (14-LILR-7anos).

\section{Reagindo da mesma maneira com o agressor}

Por fim, dentro da reação das crianças diante dos maus tratos contra idosos, foi identificada mais uma categoria, que corresponde a reagir da mesma maneira com o agressor, ou seja, agrediriam o mesmo, física ou verbalmente.

la pegar um pedaço de tijolo e tacava nele (8-MWE-10anos). la, ia dar um pé na bunda (19-GRC-7anos).

Em uma investigação brasileira, foi questionado aos idosos o que eles consideravam ser maus tratos e $65 \%$ disseram ser a forma preconceituosa como são tratados pela sociedade, não relacionando exclusivamente a violência física ${ }^{(5)}$. Um estudo realizado com 50 idosos de grupos de convivência do arquipélago de Fernando de
Noronha-PE objetivou apreender as representações sociais da violência na velhice e encontrou situações como abandono (35\%), desrespeito (29\%), negligência (18\%) e agressão física $(18 \%)^{(17)}$. A concepção de familiares que coabitam com idosos sobre a violência e maus tratos também foi investigada e a definição para esses inclui deixar sozinho, não alimentar, não cuidar e restringir o idoso a frequentar locais públicos ${ }^{(18)}$.

Logo, adultos conseguem ter uma visão ampliada e reconhecer os diferentes tipos de maus tratos existentes, o que não acontece com as crianças, que tendem a centrar-se em dados concretos e perceptíveis no mundo delas, possuindo explicações superficiais sobre o

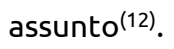

No presente estudo, não foi questionado às crianças qual a concepção delas sobre maus tratos, mas, como podemos observar, relacionaram os mesmos à violência física, já que algumas falaram apanhar, bater e brigar; mas também citaram violência verbal, pois utilizaram o termo xingar.

Um estudo que investigou a percepção acerca da violência, de 20 crianças entre cinco e 11 anos, residentes na periferia de Fortaleza-CE, concluiu que o conceito é associado principalmente a sequestro, rapto, bater, relação de poder e agressão verbal, e que elas conseguem reconhecer isso como errado(19). Outra investigação trabalhou a temática da violência com 40 crianças de seis a 15 anos, sendo que a definição de violência esteve relacionada principalmente a agressões físicas, atos criminosos e tudo que fere o outro, tanto física quanto psicologicamente(20). Já as oito crianças de Niterói, quando questionadas sobre violência, citaram, principalmente, a física e a sexual e, apesar de não falarem diretamente sobre a violência psicológica, contam situações em que é possível identificá-la(11).

Assim, de acordo com o presente estudo e com outros estudos destacados acima(11-12,19-20), que abordaram a temática dos maus tratos no Brasil, as crianças tendem a focar na violência física e verbal, sendo essas as mais percebidas por elas. Esse fato pode ser justificado, pois há na sociedade em geral uma dificuldade para definir o fenômeno da violência e seus diferentes tipos. Isto porque o mesmo é pouco abordado e discutido nas escolas e a forma como a violência é reproduzida pela mídia, com foco em atos de criminalidade, estimulam essa visão reducionista ${ }^{(12)}$. 
Em um estudo que visou compreender a violência e os maus tratos, sob a ótica de familiares que coabitam com idosos, foi destacado que certas atitudes que o idoso tem e teve durante a vida podem desencadear a agressão por parte dos familiares ${ }^{(18)}$. Essa fala pode estar relacionada ao fato de que, no presente estudo, 9,6\% das crianças disseram que agrediriam a pessoa que estaria maltratando um idoso, reagindo da mesma maneira. Isso pode ser reflexo, de alguma forma, de maus tratos que tenham presenciado dentro de sua própria casa, ou em ambiente escolar, por exemplo, o que suscitaria o desenvolvimento de atos agressivos nas crianças.

Sobre esse aspecto, em entrevistas com 502 crianças do ensino fundamental II da cidade de São Paulo-SP, foi identificado que quando o ambiente familiar é percebido como oferecedor de suporte e acolhedor, há uma menor expressão de violência na escola e, opostamente, que o aumento da mesma pode estar relacionado aos maus tratos na família, sendo que estes influenciam os comportamentos violentos nas crianças ${ }^{(21)}$.

Uma investigação realizada com 50 idosos ${ }^{(17)}$ mostrou que os mesmos apostam em medidas preventivas contra a violência, como a punição (45\%), denúncia (27\%), políticas públicas (18\%) e cuidados $(8 \%)^{(17)}$. Em outro estudo conduzido com oito crianças ${ }^{(11)}$, a polícia foi mencionada como referência de segurança e como medida para acabar com a violência, e também foi citada a importância da conversa, união e respeito(11), o que reforça os dados do presente estudo, onde $46,1 \%$ das crianças se referem a ajudar o idoso que está sendo agredido de alguma forma, seja esta ajuda policial ou não.

Investigação conduzida com 315 idosos revelou que $34,8 \%$ dos idosos e $38,9 \%$ das idosas confirmaram ter sido vítimas de violência psicológica, física e negligência. Aproximadamente $20 \%$ dos idosos reagiram e somente $4,5 \%$ denunciaram. Quase metade dos idosos disse saber a qual órgão público poderia denunciar a agressão, porém nenhum soube nomeá-lo(14).

No presente estudo, 36,5\% das crianças não sabiam o que fariam ou não fariam nada, caso vissem um idoso sendo maltratado. Esse dado pode ser justificado pelo medo que possuem de serem repreendidas por tomarem alguma atitude, ou simplesmente por não saberem o que fazer. Essa omissão é o que, de acordo com a literatura, torna os casos de maus tratos não $\operatorname{conhecidos}^{(8)}$, pois, por medo de sofrerem alguma consequência ou por não saberem como denunciar, as pessoas não o fazem e assim os agressores acabam não sendo conhecidos ${ }^{(3,7,14)}$. Nesse caso, as agressões podem se tornar frequentes e a prevalência de maus tratos fica difícil de ser estabelecida, dificultando o planejamento de intervenções ${ }^{(14,17)}$.

Como citado, a prevalência de maus tratos contra idosos ainda não está clara na literatura. Muitos estudos buscam estimar a mesma, porém avaliam apenas as denúncias realizadas em órgãos especializados, e os casos em que o idoso ou alguma outra pessoa denuncia são raros, já que normalmente a violência é subnotificada(1415,17). Assim, a educação para aqueles que cuidam de idosos é importante e deve ser usada como uma forma de prevenção, já que, se forem conhecidos os tipos de maus tratos e as formas de denúncia e punição, as pessoas estarão mais instrumentalizadas para reportar o mesmo ${ }^{(22)}$.

\section{Sentimento das crianças diante dos maus tratos contra idosos}

Este tema contempla três categorias: Ficando triste/chateado, que foi a mais citada; Reconhecendo o idoso como frágil e Não identificando o sentimento. As mesmas serão apresentadas a seguir.

\section{Ficando triste/chateado}

Nesta categoria foram agrupadas as falas de crianças que disseram que ficariam tristes ou chateadas no caso de presenciarem uma cena de maus tratos aos idosos.

Num gosto, fico triste (5-GCN-10anos).

Eu fico chateado, num sei, tristeza (7-KCS-10anos).

[...] porque eu num gosto que ninguém maltrata os idosos, eu fico triste (19-GRC-7anos).

A maioria das crianças desta categoria não soube explicar por que se sentiriam tristes ou chateadas, apenas manifestaram o sentimento. Apesar disso, muitas delas, ao serem questionadas sobre a sua reação, disseram que fariam algo para ajudar (reações já apresentadas na categoria anterior).

\section{Reconhecendo o idoso como frágil}

Outras crianças possuem o sentimento de que idosos são pessoas frágeis e merecem ser bem tratadas.

Porque os mais velhos têm que ser bem tratados (9-HVS9anos). 
Porque eles não têm como se defender, já estão mais velhinhos (12-KHM-8anos).

Porque maltrata as pessoas idosas e num pode, porque elas são muito lentas e pessoas que maltratam elas podem até bater, e num pode fazer isto (21-GBP-9anos).

\section{Não identificando o sentimento}

Houve também algumas crianças que não conseguiram identificar o sentimento que possuem diante dos maus tratos contra os idosos.

Não fiquei triste, nem pensei nisso (35-GMRS-8anos).

Apesar de não conhecerem detalhes sobre o assunto ou de a maioria nunca ter presenciado um idoso sendo maltratado, $71,7 \%$ das crianças disseram que ficariam tristes se presenciassem uma cena dessas. Este dado é importante, pois mostra a sensibilização delas em relação ao tema.

Quando as 2.077 crianças da Nova Zelândia foram questionadas a respeito do que sentem ao presenciar a violência contra elas próprias, contra os adultos, ou na mídia, a maioria reportou sentir medo, mas também foram citados sintomas como não conseguir dormir ou não conseguir parar de pensar no assunto(9). Em Fortaleza-CE, quando questionada a percepção de oito crianças entre cinco e 11 anos em relação à violência doméstica, uma das categorias que emergiu das falas foi "fico muito triste quando eles estão brigando"(10). Em outro estudo já citado, o assunto violência deixou as crianças de nove a 11 anos entrevistadas tristes e inseguras, apresentando sentimentos de angústia, pena, revolta, injustiça e medo(11).

Esses dados corroboram com o presente estudo quando se referem à tristeza sentida pelas crianças em relação aos maus tratos, que foi reportada pela maioria delas, e também ao sentimento de pena e injustiça em relação às pessoas que sofrem os maus tratos. Apesar disso, o presente estudo agrega conhecimento novo, pois incorpora a visão da criança em relação aos maus tratos cometidos especificamente contra idosos.

A partir de evidências disponíveis na literatura e sua relação com o presente estudo, foi possível conhecer um pouco mais sobre os maus tratos contra os idosos. Os fatores relacionados à violência contra idosos identificados foram:
- violência normalmente intrafamiliar/domiciliar $\Gamma^{(5,7,14-15)}$;

- está relacionada ao convívio intergeracional(14,23);

- o agressor geralmente é do sexo masculino e de meia idade, normalmente filho do idoso ${ }^{(5,8,15,24)}$;

- há a associação do agressor com dependência química ${ }^{(5,7,24)}$;

- a maioria das vítimas são mulheres, apesar de já haver uma mudança neste perfil(5,8,23-24);

- a idade do idoso varia, já que alguns estudos apontam ser entre 60-69 anos ${ }^{(8,15)}$ e outros em idosos mais velhos ${ }^{(5,23-24)}$;

- os idosos são isolados socialmente ${ }^{(7,23)} \mathrm{e} / \mathrm{ou}$ dependentes ${ }^{(5,23)}$ e

- os idosos são a única fonte de renda familiar ${ }^{(5,23)}$.

De acordo com a $\mathrm{OMS}^{(4)}$, há necessidade de aumentar a consciência política sobre os maus tratos contra os idosos e não somente conscientizar a população. O envolvimento da população com esse assunto é que permitirá planejar e executar políticas públicas adequadas, já que a ocorrência de alguns agravos contra idosos, como mortes por causas externas, acidentes, violência e maus tratos, tende a crescer significativamente ${ }^{(17)}$.

O cuidado com o idoso é de responsabilidade compartilhada do Estado, da família e da população, e o enfrentamento do problema da violência contra essa população deve partir dessas três esferas. O profissional de enfermagem, por lidar diariamente com idosos e suas famílias nos serviços de saúde, tem um papel importante nesse processo, inclusive por meio de ações educativas, atuando na prevenção da violência(25).

As crianças devem ser educadas e ensinadas a buscar ajuda caso presenciem situações de violência(9). É importante que haja uma articulação entre a educação e a saúde, principalmente com as USF trabalhando em conjunto com as escolas, para abordarem o tema da violência(11), principalmente contra os idosos, uma população considerada de risco.

\section{CONCLUSÃO}

Este estudo objetivou explorar os sentimentos e atitudes de crianças diante dos maus tratos aos idosos, não tendo esgotado o assunto, mas contribuindo para ampliar a compreensão de temática relevante, cuja produção de conhecimento ainda é escassa. 
As crianças da presente investigação tentariam ajudar de alguma forma o idoso que sofresse agressão, caso presenciassem uma cena, e relataram se sentir tristes/chateadas com a situação.

Crianças muitas vezes são protegidas de questões relevantes e de grande importância social, como os maus tratos aos idosos. Explorar seus conhecimentos foi importante, pois torna possível que profissionais das áreas da saúde e educação procurem estratégias de informá-las sobre o assunto, ajudando-as a se preparar para o mundo em que vivem. A importância do respeito com as pessoas de todas as faixas etárias, inclusive idosos, deve ser destacada, bem como as formas e caminhos da denúncia, quando necessário.

Profissionais de saúde atuantes na atenção básica devem fazer parcerias com escolas e outros locais frequentados por crianças e desenvolver estratégias de educação das mesmas, tratando dos mais diversos assuntos, entre eles a violência contra idosos. As intervenções em âmbito familiar são de suma importância, já que, de acordo com dados apresentados, a violência acontece majoritariamente na própria casa do idoso, o que pode levar a um aumento da violência da criança na escola.

O fato de os dados terem sido coletados com crianças que residem com idosos pode levar a uma dupla interpretação dos resultados. Morar com idosos pode ser um fator de proteção, no caso das crianças que possuem uma boa convivência com eles, na maioria dos casos seus avós. Isso pode fazer com que o relacionamento delas com o idoso que mora e com outros idosos da comunidade seja bom e elas se tornem defensoras dos mesmos. Ou ainda pode ser um fator dificultador, caso o relacionamento entre eles não seja bom, ou caso haja algum tipo de violência domiciliar contra o idoso da casa, que leve a criança a se espelhar no agressor e se tornar uma pessoa violenta.

Devido a isso, sugerem-se entrevistas com crianças que não morem com idosos, de outras faixas etárias, e até abordando outras questões, como a concepção delas sobre os maus tratos.

O fato de terem sido feitas perguntas abertas às crianças pode ter intimidado as mesmas a falarem sobre o assunto. Portanto, a utilização de metodologias diferenciadas como, por exemplo, o uso de objetos intermediários para conhecer os sentimentos e atitudes das crianças diante dos maus tratos aos idosos, pode ser válida em estudos posteriores.

Devido ao crescimento do número de idosos na população, a formação de profissionais de saúde deve se voltar também para a área gerontológica, não apenas informando sobre o envelhecimento, mas formando profissionais capazes de respeitar suas peculiaridades e instrumentalizar pessoas a respeito da velhice.

De maneira geral, as crianças se mostraram capazes de compreender a importância desta temática na relação com os idosos e manifestaram que teriam atitudes de proteção frente ao ato violento. Assim, a educação das mesmas é fundamental, e os profissionais de saúde e educação são responsáveis por disseminar conhecimento para que esse comportamento se perpetue durante toda a vida, e as mesmas não cometam atos de maus tratos contra os idosos no futuro.

\section{AGRADECIMENTO E FINANCIAMENTO}

Ao Programa de Pós Graduação em Enfermagem da UFSCar e ao financiamento da Fundação de Amparo à Pesquisa do Estado de São Paulo (FAPESP) pela possibilidade de desenvolvimento deste estudo.

geriatria e gerontologia. 2a. ed. Rio de Janeiro: Guanabara Koogan; 2006. p. 1152-7.

6. World Health Organization. World report on violence and health. Geneve: World Health Organization; 2002. 372p.

7. Santos ACPO, Silva CA, Carvalho LS, Menezes MR. A construção da violência contra idosos. Rev. Bras. Geriatr. Gerontol. [Internet]. 2007 [acesso em: 30 set 2013];10(1). Disponível em:

http://revista.unati.uerj.br/scielo.php?script=sci_arttext\&pid=S1 809-98232007000100009\&lng=pt.

8. Gaioli CCLO, Rodrigues RAP. Occurrence of domestic elder abuse. Rev Lat Am Enfermagem [Internet]. 2008 [acesso em: 30 set 2013];16(3):465-470. Disponível em: http://dx.doi.org/10.1590/S0104-11692008000300021. 
9. Carroll-Lind J, Chapman J, Raskaukas J. Children's perceptions of violence: the nature, extent and impact of their experiences. Social Policy Journal of New Zealand [Internet]. 2011 [acesso em: 30 set 2013];(37). Disponível em: http://www.msd.govt.nz/about-msd-and-our-work/publicationsresources/journals-and-magazines/social-policyjournal/spj37/37-childrens-perceptions-of-violence.html. 10. Bezerra LLAL, Nogueira JLA, Fernandes DLA, Mamede ALS, Valdês MTM, Frota MA. Violência doméstica sob a ótica criança de periferia. Cadernos ESP [Internet]. 2010 [acesso em: 30 set 2013];4(1):9-13. Disponível em:

http://www.esp.ce.gov.br/cadernosesp/index.php/cadernosesp/ article/view/28.

11. Barreto FOC. Violência nas relações familiares na visão de crianças de uma escola municipal em Niterói [dissertação]. Rio de Janeiro: Instituto de Estudos de Saúde Coletiva/UFRJ; 2011. $93 \mathrm{p}$.

12. Monteiro TA, Saravali EG. As causas da violência segundo a visão de crianças e adolescentes. Revista LEVS [Internet]. 2010 [acesso em: 30 set 2013];6(6):75-89. Disponível em: http://www2.marilia.unesp.br/revistas/index.php/levs/article/vi ew/1128.

13. Burke JL. Young children's attitudes and perceptions of older adults. Int J Aging Hum Dev. 1981-1982;14(3):205-22. 14. Melo VL, Cunha JOC, Falbo Neto GH. Maus-tratos contra idosos no município de Camaragibe, Pernambuco. Rev. Bras. Saude Mater. Infant. [Internet]. 2006 [acesso em: 30 set 2013];6 Suppl 1:s43-8. Disponível em: http://dx.doi.org/10.1590/S1519$\underline{38292006000500006 .}$.

15. Souza ER, Ribeiro AP, Atie S, Souza AC, Marques CC. Rede de proteção aos idosos do Rio de Janeiro: um direito a ser conquistado. Cien Saude Colet [Internet]. 2008 [acesso em: 30 set 2013];13(4):1153-63. Disponível em: http://dx.doi.org/10.1590/S1413-81232008000400011. 16. Bardin L. Análise de conteúdo. 4a. ed. Rio de Janeiro: Edições 70; 2008.

17. Araújo LF, Lobo Filho JG. Análise psicossocial da violência contra idosos. Psicol. Refl. Crít. [Internet]. 2009 [acesso em: 30 set 2013];22(1):153-60. Disponível em:

http://dx.doi.org/10.1590/S0102-79722009000100020. 18. Leite MT, Hildebrandt LM, Santos AM. Maus-tratos a idosos no domicílio: concepção de familiares. Rev. Bras. Geriatr. Gerontol. [Internet]. 2008 [acesso em: 30 set 2013];11(2). Disponivel em:

http://revista.unati.uerj.br/scielo.php?script=sci_arttext\&pid=S1 809-98232008000200007\&lng=pt\&nrm=iso.

19. Frota MA, Nogueira JLA, Bezerra LLAL, Lima PRF, Sousa Filho AO, Costa RO. Percepção da criança da periferia de Fortaleza - Ceará acerca da violência. Cogitare enferm [Internet]. 2010 [acesso em: 30 set 2013];15(3):427-32. Disponivel em:

http://ojs.c3sl.ufpr.br/ojs2/index.php/cogitare/article/view/18883.

20. Monteiro TA, Saravali EG. Psicogênese da noção de violência: um estudo evolutivo a partir da perspectiva piagentiana. Educação. Revista do Centro de Educação [Internet]. 2011 [acesso em: 30 set 2013];36(2):279-96. Disponível em: http://www.redalyc.org/articulo.oa?id=117119168008.

21. Tortorelli MFP, Carreiro LRR, Araújo MV. Correlações entre a percepção da violência familiar e o relato de violência na escola entre alunos da cidade de São Paulo. Psic.: Teor. e Pesq. [Internet]. 2010 [acesso em: 30 set 2013];12(1):32-42. Disponível em:

http://pepsic.bvsalud.org/scielo.php?script=sci arttext\&pid=S15 16-36872010000100004\&lng=pt\&nrm=iso.

22. Knapp R. The impact of interpersonal violence on health care. Nurs Clin North Am [Internet]. 2011 [acesso em: 30 set 2013];46(4):465-70. Disponível em:

http://dx.doi.org/10.1016/j.cnur.2011.08.004.
23. Souza AS, Meira EC, Neri IG, Silva JA, Gonçalves LHT. Fatores de risco de maus-tratos ao idoso na relação idoso/cuidador em convivência intrafamiliar. Textos Envelhecimento [Internet]. 2004 [acesso em: 30 set 2013];7(2). Disponível em: http://revista.unati.uerj.br/scielo.php?script=sci_arttext\&pid=S1 517-59282004000200005\&lng=pt\&nrm=iso.

24. Souza JAV, Freitas MC, Queiroz TA. Violência contra os idosos: análise documental. Rev Bras Enferm [Internet]. 2007 [acesso em: 30 set 2013];60(3):268-72. Disponível em: http://dx.doi.org/10.1590/S0034-71672007000300004. 25. Florêncio MVL, Ferreira Filha MO, Sá LD. A violência contra o idoso: dimensão ética e política de uma problemática em ascensão. Rev. Eletr. Enf. [Internet]. 2007 [acesso em: 30 set 2013];9(3):847-57. Disponível em:

http://www.fen.ufg.br/revista/v9/n3/v9n3a23.htm.

Artigo recebido em 17/08/2012.

Aprovado para publicação em 29/05/2013.

Artigo publicado em 30/09/2013. 